See discussions, stats, and author profiles for this publication at:

https://www.researchgate.net/publication/267153220

\title{
What About Nonprogrammatic Factors? Women's Perceptions of Staff and Resident Relationships in a...
}

Article in Journal of Offender Rehabilitation · January 2014

DOI: $10.1080 / 10509674.2013 .861315$

CITATIONS

4

3 authors:

Andrea Cantora

University of Baltimore

6 PUBLICATIONS 5 CITATIONS

SEE PROFILE

\section{Melinda D. Schlager}

University of North Texas at Dallas

11 PUBLICATIONS 121 CITATIONS

\section{READS}

29

SEE PROFILE 
This article was downloaded by: [J ohn J ay College of Criminal J ustice]

On: 07 May 2015, At: 05:55

Publisher: Routledge

Informa Ltd Registered in England and Wales Registered Number: 1072954 Registered office: Mortimer House, 37-41 Mortimer Street, London W1T 3J H, UK

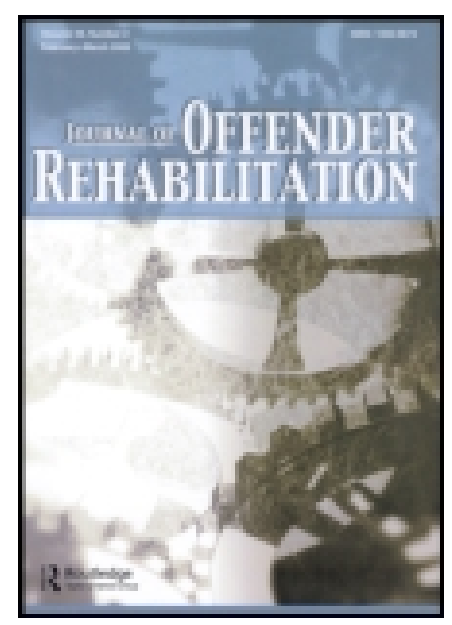

CrossMark
J ournal of Offender Rehabilitation

Publication details, including instructions for authors and subscription information:

http:// www.tandfonline.com/loi/ wjor20

\section{What About Nonprogrammatic Factors? Women's Perceptions of Staff and Resident Relationships in a Community Corrections Setting}

Andrea Cantora $^{a}$, J eff Mellow ${ }^{b} \&$ Melinda D. Schlager ${ }^{c}$

${ }^{a}$ University of Baltimore, Baltimore, Maryland, USA

${ }^{b}$ J ohn J ay College of Criminal J ustice, New York, New York, USA

${ }^{c}$ Texas A\&M University-Commerce, Commerce, Texas, USA Published online: $21 \mathrm{~J}$ an 2014.

Click for updates

To cite this article: Andrea Cantora, J eff Mellow \& Melinda D. Schlager (2014) What About Nonprogrammatic Factors? Women's Perceptions of Staff and Resident Relationships in a Community Corrections Setting, J ournal of Offender Rehabilitation, 53:1, 35-56, DOI: 10.1080/ 10509674.2013.861315

To link to this article: http:// dx. doi.org/ 10.1080/ 10509674.2013.861315

\section{PLEASE SCROLL DOWN FOR ARTICLE}

Taylor \& Francis makes every effort to ensure the accuracy of all the information (the "Content") contained in the publications on our platform. However, Taylor \& Francis, our agents, and our licensors make no representations or warranties whatsoever as to the accuracy, completeness, or suitability for any purpose of the Content. Any opinions and views expressed in this publication are the opinions and views of the authors, and are not the views of or endorsed by Taylor \& Francis. The accuracy of the Content should not be relied upon and should be independently verified with primary sources of information. Taylor and Francis shall not be liable for any losses, actions, claims, proceedings, demands, costs, expenses, damages, and other liabilities whatsoever or howsoever caused arising directly or indirectly in connection with, in relation to or arising out of the use of the Content.

This article may be used for research, teaching, and private study purposes. Any substantial or systematic reproduction, redistribution, reselling, loan, sub-licensing, systematic supply, or distribution in any form to anyone is expressly forbidden. Terms \& 


\title{
What About Nonprogrammatic Factors? Women's Perceptions of Staff and Resident Relationships in a Community Corrections Setting
}

\author{
ANDREA CANTORA \\ University of Baltimore, Baltimore, Maryland, USA \\ JEFF MELLOW \\ John Jay College of Criminal Justice, New York, New York, USA \\ MELINDA D. SCHLAGER \\ Texas AGM University-Commerce, Commerce, Texas, USA
}

\begin{abstract}
This study examines how women perceive nonprogrammatic factors while residing at a community corrections facility. Qualitative interview data was used to understand how women perceive and experience the social environment of the facility, and how these experiences may contribute to their adjustment and motivation. Findings include various themes that emerged during data analysis, including perceptions of staff characteristics and interactions, the environmental context, and relationships with residents. Implications for evidence-based practices and genderresponsive treatment are discussed.
\end{abstract}

KEYWORDS community corrections, correctional programming, female offenders, offender rehabilitation, qualitative research

\section{INTRODUCTION}

Much of the research on correctional program practices focus on aspects of a program that are necessary for producing successful outcomes for both female and male offenders. Although there is much debate in the field about

Address correspondence to Andrea Cantora, School of Criminal Justice, College of Public Affairs, University of Baltimore, 1420 North Charles St., Ste. AC-239, Baltimore, MD 21201, USA. E-mail: acantora@ubalt.edu 
treating these two groups differently, core principles of effective practices have been successfully applied to both groups. These principles-known as the risk-need-responsivity model (RNR)-dominate the correctional rehabilitation literature (Andrews \& Bonta, 2010; Andrews, Zinger, Hoge, Bonta, Gendreau, \& Cullen, 1990; Gendreau, 1996). Core features of the RNR model include: identify risk level and enhance services for moderate to high-risk individuals; treat multiple criminogenic needs; deliver treatment based on social learning and cognitive behavioral approaches; and adapt treatment to fit individual client characteristics (Andrews \& Bonta, 2010). Regardless of gender, programs that incorporate these key components are found to be effective at reducing recidivism (Andrews et al., 1990; Dowden \& Andrews, 1999; Gendreau \& Goggin, 1996).

The correctional rehabilitation literature has also identified certain nonprogrammatic features that contribute to successful program outcomes (Andrews, 2011; Palmer, 1995). These include staff-client interactions, characteristics of staff, client demographic characteristics, and setting features (Andrew, 2011; Andrews \& Kiessling, 1980; Dowden \& Andrews, 2004; Palmer, 1995). While attention has been paid to staff characteristics, and staff-client interactions (Andrews \& Kiessling, 1980; Dowden \& Andrews, 2004; Palmer, 1995), the literature on RNR does not provide guidelines on what type of environment is appropriate for rehabilitating offenders, other than providing services in a community setting (Andrews et al., 1990; Andrews, 2006). Characteristics of the program environment are argued to be important for the rehabilitative process, especially for women offenders. The substance abuse and gender-responsive treatment literature identifies evidence-based, and promising strategies for developing the appropriate rehabilitative environment. Creating an environment that is both physically and psychologically safe has been identified as a crucial component of working specifically with female offenders, including developing connectedness, safety, and an environment that is supportive (Bloom, Owen, \& Covington, 2003).

To further elaborate on the previous points, this article begins with the literature that distinguishes between programmatic and nonprogrammatic factors. Gaps in this research will be highlighted. Next, nonprogrammatic factors reviewed in the gender-responsive and substance abuse treatment literature will be discussed. Both literatures provide support for enhancing nonprogrammatic features (Bloom et al., 2003; Koons, Burrow, Morash, \& Bynum, 1997; Simpson, 1997). Following the literature review, a qualitative study designed to understand women's perceptions of nonprogrammatic factors will be presented. Specifically, this study examines women's perceptions of staff characteristics and interactions, the environmental context, and resident relationships in a community correction setting. We argue that aspects of the program setting play a powerful role in how women perceive the rehabilitative environment. We conclude the article with recommendations for enhancing in-program relationships, and rethinking the benefits 
and drawbacks of placing women in reentry programs far from their home community. We further argue that more research is needed to empirically assess whether factors outside the RNR model play a role in program adjustment, motivation, and outcomes.

\section{PROGRAMMATIC AND NONPROGRAMMATIC FACTORS}

For over 40 years, researchers have been working to identify best practices in correctional rehabilitation programs. Martinson's famous 1974 article that declared "nothing works" prompted researchers to truly question "what works" in rehabilitating offenders. Today, the knowledge base on effective practices is rich with empirical support. At the heart of this is the RNR model. The risk principle of the model emphasizes using actuarial assessment tools to predict criminal behavior, and reserve treatment interventions for those with moderate to high-risk scores. Research has shown that when treatment is delivered to high-risk offenders reductions in recidivism occur (Lowenkamp, Latessa, \& Smith, 2006). The need principle involves matching treatment services with offender's criminogenic needs (e.g., employment, education, substance abuse, and antisocial behavior). One of the strengths of identifying and targeting criminogenic needs is that through treatment they can be changed and ultimately reduce future criminal behavior (Andrews, Bonta, \& Hoge, 1990). The principle of general responsivity involves delivering treatment based on social learning and cognitive behavioral approaches. Whereas specific responsivity involves adapting treatment approaches to fit individual client characteristics (Andrews \& Bonta, 2010). Many metaanalytic reviews have provided a wealth of evidence that when programs incorporate the core principles of the RNR model reductions in recidivism occur (Andrews et al., 1990; Dowden \& Andrews, 1999; Lipsey, 1995).

Within the RNR model are certain programmatic features related to the type of intervention delivered. What we do with offenders while they are in programs should not reflect punitive or control-oriented intervention models (Latessa, Cullen, \& Gendreau, 2002). Instead, the most successful interventions should be cognitive-behavioral treatment, skill oriented interventions, family treatment, and multimodal approaches (Latessa et al., 2002; Palmer, 1995). The most effective strategy is a combination of treatment interventions targeting multiple criminogenic needs (Palmer, 1995). According to Palmer it is simply not enough to implement and evaluate whether certain programmatic factors (e.g., type of intervention) work, we must examine nonprogrammatic factors to understand why programs do, or do not, work.

Palmer (1995) defined nonprogrammatic factors as "a wide range of factors and conditions often centered on structural and quantitative aspects that do no focus on program content" (p. 104). Important in this definition are factors unrelated to program content. Palmer described four types 
of nonprogrammatic factors including staff characteristics, staff-client interactions, offender characteristics, and the treatment setting. Andrews (2011) recently defined nonprogrammatic factors as core correctional practices, staffing, management, program integrity, setting, and individual characteristics (i.e., age, gender, and ethnicity).

The most well researched nonprogrammatic factors are the core correctional practices (CCP). Andrews and Kiessling (1980) identified five CCP dimensions linked to successful program outcomes. These practices involve staff characteristics such as: effective use of authority; display anticriminal modeling and reinforcement; problem solving; use of community resources; and the ability to develop an interpersonal relationship with clients. Dowden and Andrews' (2004) meta-analysis confirmed support for incorporating these dimensions into correctional programs. They found that staff characteristics enhance the effects of treatment programs that incorporate the RNR principles. Palmer's (1995) meta-analysis also found support for CCP dimensions. He found that clients have greater changes in attitudes and behavior when they have good relationships with staff, hold positive views of program employees, and are matched closely with those that share similar characteristics (Palmer, 1995). Additionally, researchers find that staff with empathetic, warmhearted, and sense of humor qualities are most successful at motivating participants (Dowden \& Andrews, 2004; McMurran \& Ward, 2004).

Of particular importance to this study was Palmer's (1995) research on type of correctional setting. Palmer reviewed studies examining setting factors and found success rates were higher in community programs versus institutional settings. However, the difference in success between settings was also a product of client characteristics (e.g., maturity levels, amenability, and degree of problems). According to Palmer, program setting involves more than type of facility (institution vs. community), it also refers to management and social-climate dimensions. Palmer did not, however, elaborate on aspects of social climate (or environment) in his 1995 article, but did emphasize that environmental features be included when studying correctional program effectiveness. Earlier researchers defined the term social climate as a "set of organizational properties or conditions that are perceived by its members and are assumed to exert a major influence on behavior" (Wright, 1985, p. 258). Specific environment attributes have been measured in early research including inmates' perceptions of privacy, safety, freedom, and support (Moos, 1975; Toch, 1977; Wright, 1993). While some researchers have used similar scales to examine inmates' perceptions of the prison environment (Day, Casey, Vess, \& Huisy, 2012; Smith, Maume, \& Reiner, 1997), this area remains underresearched.

Research on the role environment plays in program effectiveness is even more limited on community correction settings. Aspects of program context such as social relationships among clients; perceptions of safety 
and security; physical characteristics of the internal setting (e.g., sleeping accommodations, visitation area, and privacy); and the neighborhood where programs are situated are areas in need of further research. None of these features are discussed in the RNR literature, but are prevalent in the genderresponsive and substance-abuse treatment literatures.

\section{GENDER RESPONSIVE NONPROGRAMMATIC FACTORS}

Since the 1990s, researchers have investigated "promising" correctional strategies (Austin, Bloom, \& Donahue, 1992; Bloom et al., 2003; Koons et al., 1997; Morash, Bynum, \& Koons, 1995), and empirically-based programs and practices specifically for women (Gehring Van Voorhis, \& Bell, 2010; Messina, Grella, Cartier, \& Torres, 2010; Wright, Van Voorhis, Salisbury, \& Bauman, 2009). The overarching framework for gender-responsive strategies was developed by Bloom and colleagues (2003). Two of the key principles they developed involve (a) creating a safe, respectful environment and (b) creating programs that are relational and promote healthy connections to loved ones and the community. These principles emphasize developing a supportive environment and promoting healthy relationships among women in the program setting. This involves developing a therapeutic environment by creating a culture of belonging, openness, participation, and empowerment (Covington \& Bloom, 2006). Developing a supportive environment is grounded in relational theory (Covington, 1998). Forming trusting interpersonal relationships with others is the core of the relational model (Covington, 1998; Gilligan, 1982; Miller, 1986). Women offenders often come from backgrounds of disconnected relationships, including physical, emotional, and sexual abuse perpetrated by intimate others. Covington (2003) argued that it is the positive connections in women's lives that help them to grow and develop a sense of self-worth.

A study by Koons et al. (1997) confirmed the importance of incorporating some of these principles into female correctional program design. They identified setting factors that program administrators perceived linked to successful outcomes. This included the social environment where women had peer support, open communication, and a "homey atmosphere" away from the general inmate population. They also perceived women-only groups as a place to talk about sensitive issues, and where women can form "sisterlike relationships" with other peers. To further emphasize the importance of therapeutic environment, research suggests that personal hostilities among female residents and the inability to get along may impact program adjustment, outcomes (Kendall, 1993), and criminal thinking (Van Tongeren \& Klebe, 2009).

Developing a supportive, or therapeutic, environment is common in the substance abuse literature. According to Broome, Knight, Knight, Hiller, 
and Simpson (1997), therapeutic relationships entail both the development of supportive bonds between clients and staff, and peer-to-peer connections. Part of the therapeutic environment involves creating a setting where clients feel psychologically safe. As defined by Hiller, Knight, Leukefeld, and Simpson (2002), psychological safety refers to the ability to trust treatment staff and peers. High levels of psychological safety are related to treatment motivation (Hiller et al., 2002). Research on substance abuse programs finds that developing strong, supportive relationships with staff and peers increases therapeutic engagement (Welsh \& McGrain, 2008), motivation (Hiller et al., 2002), treatment retention, and reduces substance use (Simpson, 1997).

The literature discussed above illustrates the limited research on nonprogrammatic factors, especially the therapeutic culture of program settings. To explore some of the nonprogrammatic features discussed above this qualitative study seeks to examine women's perceptions of staff characteristics and interactions, the environmental context, and resident relationships in a community correction setting. How these experiences contribute to women's adjustment and motivation are also explored.

\section{PROGRAM CONTEXT}

This article is based on research conducted at a female residential community release program (hereafter referred to as "the halfway house,") in New Jersey. At the halfway house, residents remain under the custody of the New Jersey Department of Corrections (NJDOC) and the state's parole board, limiting their community movement and holding them accountable for all activities. The halfway house follows principles of the RNR model including the use of the Level of Service Inventory-Revised (LSI-R), cognitive-behavioral treatment groups, and motivational interviewing techniques. The environment is not designed to be therapeutic, although on-site treatment groups and weekly house government meetings are centered on bringing residents together.

To assist in the supervision of residents, the halfway house follows a gradual phase system that provides residents with privileges as they achieve certain goals and maintain good standing in the program. Program objectives include attending job readiness class, participating in treatment groups, obtaining and maintaining employment or education, and following other goals outlined on individualized treatment plans. To help residents achieve their individual treatment goals, staff provides in-house substance abuse treatment, life skills, female-specific programming, and case management services. Women in need of additional services, such as mental health or domestic violence counseling, are referred to outside programs in the local area. 


\section{METHODS}

\section{Sample and Data Collection}

The research presented in this article is part of a larger qualitative study examining women's experiences transitioning from prison to a New Jersey community correction program. Objectives of the larger study involved examining women's pathway to prison, their experience during incarceration, the transition to the halfway house, daily life at the house, reentry needs, and expectations for reentry to the community. All women residing at the community correction facility between June 2007 and November 2007 were eligible to participate in this study. Forty-three women were residing in the halfway house on the day of the first interview. Thirty-five women were conveniently selected (based on availability) to be interviewed and 33 agreed to participate. Before each interview the researcher informed participants about the voluntary nature of the interview, and that confidentiality would be protected. After women agreed to participate the researcher asked for further permission to record the interview. Twenty-nine participants agreed to have the interview recorded. Each interview ranged from 30 minutes to 2 hours. The researcher used a semistructured qualitative interview protocol designed around a series of broad questions developed from previous literature. Questions addressed pathway to prison, in prison experiences, the transition to the halfway house, daily life at the house, reentry needs, family relationships, and plans for community reentry. All recorded interviews were transcribed by the researcher afterwards. The researcher took detailed notes during the four interviews where participants refused to be recorded.

Additionally, demographic and criminal history data on the sample population was collected from resident case files. Data from case files included presentence investigation reports, a correctional facility assessment, and the LSI-R conducted by halfway house staff. Lastly, the researcher made direct observations of interactions at the halfway house. Observations took place on days where the researcher conducted interviews at the facility. The researcher spent time in-between interviews at the front desk of the house, in case workers offices, in treatment groups, outside with residents during scheduled smoke breaks, and in common areas (e.g., kitchen, television room, and visitation room).

\section{Data Analysis}

Since the interviews covered a wide range of topics, the researcher identified subsections of the transcripts, and observation field notes, where respondents specifically spoke about perceptions of nonprogrammatic features of the halfway house. Specific categories related to nonprogrammatic factors were developed including staff characteristics, staff/client interactions, 
environmental context, and resident relationships. A process of initial coding then took place as a method of studying fragments of transcripts (Charmaz, 2006). As segments of transcripts were labeled, the researcher analyzed the meaning of the participants' words by writing analytical memos (Strauss \& Corbin, 1998). Codes developed during initial coding were applied during the second analytical phase of focused coding. During this phase the qualitative software program, Atlas.ti (Atlas.ti, Berlin, Germany), was used to make connections between interviews and to search for additional themes related to women's perceptions of the halfway house experience. This phase allowed the researcher to further identify aspects of the data that may have been overlooked during initial coding and also allowed for greater comparison between participants (Charmaz, 2006). Lastly, to develop a sample profile, the researcher the reviewed case files and analyzed the data using descriptive statistics related to demographic and criminal history variables.

\section{PARTICIPANT CHARACTERISTICS}

All participants were previously incarcerated in New Jersey's Edna Mahan Correctional Facility. The average length of time participants remained in the halfway house was 202 days (with a range of 51-475 days). Participants' ages ranged from 19 to 58 years old, with an average age of 39. Women were primarily African American (52\%), followed by 27\% White, and 21\% Hispanic. More than half of the sample was unmarried (61\%) and the majority had at least one child under the age of 18 (64\%). Sixty-one percent of participants had a high school diploma, or GED, yet 55\% were frequently unemployed. The majority of the sample had an extensive criminal history with $58 \%$ having three or more criminal convictions. The most frequent crimes women were convicted of were nonviolent ( $42 \%$ drug related; $27 \%$ theft; $6 \%$ other) with a lesser percentage serving time for violent offenses (24\%). According to LSI-R scores a history of substance use was common in most of the sample (64\%), however only $49 \%$ had a current substance abuse problem. An indication of a mental health problem was less frequently identified, with only $24 \%$ of the sample received previous mental health treatment. Typical mental health problems included depression, post-traumatic stress disorder, and bipolar disorder. In addition, data from participant case files indicated $46 \%$ experienced domestic violence in an intimate relationship and 30\% were sexually abused in their childhood.

\section{RESULTS}

Women's perceptions of nonprogrammatic factors and how these factors play a role in their program adjustment are discussed below. Themes are grouped under three broad categories of nonprogrammatic areas: environmental 
context, staff characteristics and relationships, and resident relationships. Observations of staff-client interactions, and daily program operations, are included to support participant perceptions.

\section{Environmental Context}

Some of the earliest impression residents had of the halfway house were the reduction in restrictions. Residents discussed having the ability to wear their own clothing, wear cosmetics, walk freely around the house, sleep in unlocked rooms, order take-out food, wash their own laundry, go shopping, use the pay phone, and participate in recreational activities off-site with staff. Participants described these as "freedoms" not afforded to them while in prison. While the physical restrictions in the setting were important, residents also described a feeling of psychological safety from the way staff treated them. Participants also spoke often about the surrounding community and viewed the halfway house as a space that they could rely on for physical safety. The following themes, "not just a number" and "protective haven," are presented to illustrate feelings of physical and psychological safety.

\section{NOT JUST A NUMBER}

Participants were asked to describe how they were treated by halfway house staff compared to correctional officers. Participants generally shared two different perceptions, they either felt that they were treated the same as they were in prison ( $n=11$; "there is no difference") or they felt that they were treated better $(n=22)$. No participant described experiencing more negative treatment at the halfway house. Those who perceived better treatment often identified halfway house staff as "nicer" and "more caring." Of the 22 who perceived halfway house staff as more caring, 13 expressed being treated like a "normal person," a "human being," and "not just a number." This was often the first time during their incarceration that they felt respected.

\footnotetext{
Oh, my God! They're a lot different. I mean, like certain officers, you know, they're all nice and they talk to you. The officers in Clinton ${ }^{1}$ [Edna Mahan Correctional Facility] they talk down to you. They have no problem calling you an F-ing bitch, this, that and the other thing, and calling out your name all the time. But like they talk to you normal here. They treat you like you're a human being, so it's not bad. (Kate)
}

Participants were also asked if they felt physically safe at the halfway house compared to their experience in prison. The majority responded that they felt physically safe throughout their incarceration, but they did not always feel respected by correctional officers. Several participants experienced verbal abuse from correctional officers while incarcerated at Edna Mahan. 
Only one participant who was verbally abused also described physical abuse by officers.

Although creating a safe and supportive environment is not considered an evidence-based principle, it is a gender-responsive principle necessary to make women feel comfortable disclosing personal problems. Participants who expressed feeling respected and supported by staff felt comfortable seeking assistance and disclosing problems. If the environment was similar to the hostility and disrespect many experienced while incarcerated, participants may have struggled to seek help and confide in staff.

\section{PROTECTIVE HAVEN}

The halfway house was often viewed as a safe place to reenter. Approximately $60 \%$ of the participants were returning to the same neighborhood where the halfway house was located. The other $40 \%$ were from communities throughout the state. For residents from the neighborhood, the halfway house was viewed as a place to gradually transition back to the area while adjusting to some of the community stressors (e.g., drug activity and drug partners). The following participant, Marie, described the halfway house as a protective haven that provided her with the opportunity to slowly readjust to her hometown neighborhood:

Because I know this is where I'm going to be [after release]. It doesn't matter
where you send me. This is where I'm going to be whether I'm clean and
sober or high and drunk. I stand a better chance of making a foundation
when I'm clean and sober, of staying clean and sober. Because my founda-
tion is already made here. You know, I don't have to come here and seek
it out. I've got, you know, a protective little haven right now, and if things
don't work out I have some place I can run back to and talk, its right here.

In Marie's case, the halfway house provided temporary shelter and support as she addressed her substance abuse. From her perspective, being released to a halfway house in her home community would increase her chance of success. Other researchers have found that some women prisoners described correctional facilities as safe havens that protected them from victimization experienced at home or on the streets (Bradley \& Davino, 2002; Henriquez \& Jones-Brown, 2000). For some women the halfway house was also perceived as a place of respite. This feeling was shared by women who were not originally from the surrounding area, and in some cases were never exposed to city life. Not only did residing in an unfamiliar place make out-of-town participants feel uneasy, but the fact that the unfamiliarity was coupled with a neighborhood characterized as disorderly and high-crime.

Participants often discussed their perceptions of the community when speaking about leaving the halfway house to search for employment. Several women expressed fears of traveling in an unfamiliar place. To Nora, the 
halfway house was a safe escape from the neighborhood conditions. As Nora explained:

One of my fears is getting lost in this area. I didn't grow up in a city ... this is a city to me. Seeing bums ... and I am not ... this is not in my neighborhood. I don't want anybody talking to me or nothing, just let me get back there [halfway house].

Jamie also described the uneasiness of navigating an unfamiliar community, and the desire to remain inside the halfway house:

I don't know nothing about this place [the neighborhood]. Like the other day when I went out on a job search this guy followed me from the front all the way to the bus station, and it was driving me crazy like is this man nuts or what? I just knew that I didn't want to go [outside to job search]. I just wanted to stay in this building, but I want to get out.

As illustrated, the geographic location of the halfway house caused psychological stress for women from the neighborhood and for those not familiar with the area. For local women, residing at the halfway house allowed for the slow transition back into a volatile environment. Learning to deal with triggers while having 24-hour support systems available relieved some of the anxiety of the transition. For unfamiliar women, the environment posed new barriers and stressors. Experiencing anxiety while navigating through a high-crime neighborhood just happened to be part of the halfway house experience. Having supportive staff help women navigate this process was a relief for many residents-local and unfamiliar alike.

\section{STAFF CHARACTERISTICS AND RELATIONSHIPS}

In this study, several characteristics of core correctional practices were both observed and discussed during interviews with residents. Consistent with the dimensions of correctional practice put forth by Andrew and Kiessling (1980), halfway house staff were observed helping residents solve daily problems, used their authority in effective ways, connected residents to community resources, and acted as the liaison between residents and parole officers (e.g., making phone calls or having in-person conversations with officers when residents had concerns/questions about their parole conditions).

During data collection two staff members were identified as most influential in the daily lives of residents. "Ms. B" was the halfway house case manager who provided residents with one-on-one support, conducted assessments, approved job assignments and furloughs, and provided daily crisis intervention. "Ms. T" was the halfway house program director responsible for the overall operations of the facility, and also ran an on-site treatment group. 
Although most of her tasks were administrative, she was very involved in the daily lives of residents. Most residents describe interactions with these two staff members when asked about staff interactions. Overall, the majority of participants described effective and emotionally supportive staff.

\section{Emotionally Supportive and Effective Staff}

When residents approached staff for help with a problem, staff would often address residents' needs immediately or, if not urgent, would schedule time to meet with them one-on-one. During interviews, the majority of participants $(n=28)$ described positive perceptions of staff, and identified situations where staff helped them solve problems and address specific needs. Participants also described staff assistance identifying and accessing community resources, such as locating education and treatment programs, referrals to local career centers, and occasionally receiving job leads.

In addition to helping residents with problems and addressing their needs, the relationships formed between residents and staff reflected many of the qualities (e.g., trustful, empathetic, and open communication) identified in RNR and gender-responsive literature. Forming trusting interpersonal relationships was a consistent theme identified throughout the interview responses on staff relationships. Participants discussed feeling respected, listened to, and were able to trust staff. Participants often discussed the emotional support offered by staff. The following resident, Marie, described a situation where staff assisted her in reconnecting with her children. Marie also described the continuous emotional support provided on a daily basis:

The staff is very helpful. Getting in touch with my kids. Just when I need somebody to talk to because I'm just going through something, you know I share where I am at. Sometimes I just feel like I'm just going to, you know, explode, and I just ask can I speak to you for a minute, you know? They call you in, let you sit down, say how you feel. It's good. They don't judge you or anything. They just be there.

Having staff readily available was an important feature of the program. Observations of staff and resident interactions confirmed participant interview responses about the supportive nature of staff-client relationships. When participants experienced personal problems, they felt that they could immediately turn to staff for help. The following resident, Kate, had the urge to use drugs and reached out to staff:

I do think they're real supportive, the staff. Like if you want to do something they help you get to that goal. I would come back and talk to them. Like if I ever felt like getting high and I thought I might do something, I would call Ms. T or Ms. B, I know. Like the other day I wanted to get high and I went and they all talked to me, so it was good. 
As illustrated, residents felt that they could rely on staff for help. Staff was also observed effectively using their authority. An example of this was observed with the halfway house policy that requires staff to send women back to prison if they do not find employment within 30 days. Residents described witnessing women returning to prison under this policy, however they noted that this typically occurred when women were not making a visible effort to secure employment. Beth provides a good description of staff extending the employment deadline to allow extra time to job search:

When I first got here they said I would give you 30 days to find a job and if you don't find a job you go back to Clinton [prison]. I was like oh my god, yeah it was day 16 and I was still looking. It took me 2 months. The reason they didn't put me on an employment contract [warning before being sent back to prison] is because they see me trying every day.

This is an illustration of staff effectively using their authority and empathizing with women who are genuinely trying to secure work and succeed in the program. Participants also responded well to staff that were honest with them. Jenny discussed the importance of emotionally supportive staff, but also valued staff that provided immediate and honest feedback about negative behavior:

They [staff] have been great. I can't say enough about Ms. T. She is hardcore, but she is a doll. She will tell you in a heartbeat that you're doing something wrong. But when you need her she's there for you too. That's the type of people you need, especially with us women like us who come through. Some of us beat up from the floor down and some of us need more understanding than others. And some of us that want to be sneaky but she sees right through it. I don't need people to pamper me or tell me things I want to hear. See I need people to tell it to me how it is. And them too would do it, most definitely.

Empathetic understanding and honest feedback were principles consistently observed in all staff-client interactions. Staff often responded to residents needs immediately. Staff-client dialog was observed to be warm, honest, and supportive. One resident described how her supportive relationship with the halfway house director contributed to her program motivation:

My support is Ms. T. She doesn't know it. I never told her. I just go to her and I ask her. Even if you are wrong she still tells you, but she is great person. I don't tell her that is what got me going, but it is her. All the staff are helpful. They really are. (Ella)

A few participants $(n=5)$ had negative perceptions of staff, including perceiving staff as unprofessional because they "favored" certain residents, did not apply the rules consistently, or were perceived as not helping to address needs. These factors were brought up in several interviews when the 
researchers asked about staff relationships. Stacy described her perception of program staff:

Operational staff are not professional in any matter. They act like ... they stereotype you because of your status of being an inmate. They have favoritism of certain inmates. Certain inmates get away with stuff that others don't. The rules and regulations are not across the board because some people can break them, some people can't.

Although Stacy, and the other participants, expressed negative perceptions generally, they were able to identify at least one staff person whom they trusted, connected with, or who had helped them in some way.

\section{RESIDENT RELATIONSHIPS}

As discussed previously, women felt physically and psychologically safe inside the halfway house, were comfortable seeking help, and felt respected by staff. The psychological security of living in a safe facility and being treated with respect are just as important as the social aspects of the setting. From a relational perspective, building trust and connection to others enables women to grow and enhance self-esteem (Covington, 2003). Within the program setting developing strong, supportive relationships with peers is important because they increases engagement (Welsh \& McGrain, 2008), motivation (Hiller et al., 2002), retention, and reduces substance use (Simpson, 1997). Interviews with women in this study indicated that the relationship dynamics amongst residents were hostile, negative, and to be avoided. The theme "avoiding chaos" provides insight into how women perceived other residents, and their strategies to avoid interactions. Regardless of the general hostile perception women had of the social dynamics, many women were able to establish small, intimate relationships. This is illustrated under the theme "friendships and support."

\section{Avoiding Chaos}

Interacting with other residents in the halfway house was a burden for many participants. Not only were participants trying to rebuild their lives, but they were also forced to deal with other women who were going through the process of transitioning from prison to the community. A total of 18 women described the inability to trust other residents, the attitudes they had to deal with every day, and the frequent confrontation over trivial things (e.g., women often became frustrated when waiting to use common areas/items such as telephones, television, and laundry facilities). Thirteen of these women repeatedly complained about living with other women and often referred 
to the environment as "chaotic." The majority of residents have been living with other incarcerated women for long periods of time (for some several years) and felt that the residents at the halfway house were the "same" type of women with whom they were incarcerated. According to Jane, "they still have their attitudes. Everybody's still got their guard up, you know, nobody trusts anybody. It's the same." Similarly, Brenda stated, "I just tolerate most of them. I get along with some of them. You still have the same tension and craziness [as prison]. You'd think being here would alleviate some of it." The fact that women were in a less-restrictive environment, with opportunities to prepare for reentry, did not seem to change the lack of trust or tension.

Participants described the prison environment as "easier" to escape the social scene, since they either had a private room or shared it with one other inmate. Similar to what Owen (1998) found in her study on women in prison, participants described developing strategies to escape others including listening to music, reading, and watching television. At the halfway house residents are assigned rooms that sleep up to 11 women, allowing for little privacy. Residents described using the same strategies they used in prison to avoid residents at halfway house:

I stay away from people. I get up, take a shower, get dressed, go downstairs and watch TV, use the phone ... other than that I stay in my room because it's all chaotic. They're still like they're kids, they act like kids. Some of them is 40 and 20 years old, they act like little kids. They keep a lot of the bullshit going on, so I don't deal with them. (Jamie)

Although Jamie, a 29-year-old resident, did not believe age played a factor in whether women engaged in arguments, 46-year-old Monique felt that younger residents caused most of the "drama" in the house. As Monique stated: "you will find a lot of young ones here. And wherever there are a bunch of young girls there is always something going on. But I don't have to involve myself in it." Monique was the only resident to discuss age as a factor behind the "drama" inside the halfway house. Residents of all ages described the environment as chaotic.

Participants often described keeping to themselves to avoid conflict with other residents. To many participants, getting involved in petty arguments was not worth the potential risk of returning to prison. Avoidance by not speaking or associating with confrontational residents was a common response. This is illustrated in the following quote by Carol, a resident who spent 15 years in prison:

I don't talk to the girls. I stay in my room. When I go home I had relationships with women and men, I can talk more. But a place like this no. You can't trust people here. Cause always someone has a motive. I just want to get out of here. I don't have time to talk to anyone, or tell anyone about my life story or tell them how my day went. 
Avoiding conflict was a difficult challenge for participants who self-identified as having a short temper. Several residents described feeling comfortable knowing that staff was always around to handle conflict. Leslie described feeling uncomfortable when other residents confronted her:

The halfway house I feel safe because I know that they're [staff] always around, they always hear everything. If somebody's arguing, all right, they know. But still there's some girls that like to start arguments with me, and it's not that I'm scared, but I feel uncomfortable because I don't want to argue or fight somebody. And I know that my temper can be put to that point, but I don't want it to be put to that point.

Similar to other studies (Owen, 1998; Kruttschnitt, Gartner, \& Miller, 2000), most women wanted to avoid the social aspect of the halfway house. Participants wanted to take care of their own lives and didn't want to associate with others: "I just do what I need to do for me, I stay focused." Most women were motivated to succeed, maintained focus on their reentry preparation, and avoided "drama" as a way of preventing their return to prison. Participants did, however, lean on one another for social support and were able to develop intimate support networks on their own.

\section{Friendships and Support}

Even though most participants described not wanting to associate with other residents because they did not trust them, or simply lacked any interest in forming new friendships, many described situations where residents provided social support. Residents discussed helping others with job leads, providing directions, sharing hygiene products, offering emotional support, helping elderly residents, and running errands for residents unable to leave the facility:

I try to stay away from all the chaos. I mean if someone needs me, I be there for them and if I can help them I give my shoulder or ears to listen. I know for a fact since I have been here they have a lot of respect for me. I have never been disrespected by any of them. If I don't feel good they ask is there anything they can do for me. But other than that I don't try to be around them. (Jaclyn)

Jaclyn is an older resident with medical needs. Although she did not specify whether her age or medical needs were the reasons for the respect, it is a possible explanation for the support she received. Another participant described developing a supportive relationship with a successful resident. Nancy described the motivation she felt by associating with a resident who owned her own business ${ }^{2}$ :

She is like a big sister because like every time I look at her like she's always smiling, she's like so positive, and she's a good person, and 
owns her own business. She's locked up like me and she's got her own business! I can get out and do something like that, you know what I mean? I really look up to that, like if she can do it I know I can.

Participants were also asked about whether they were able to form friendships with other residents. Although the majority $(n=18)$ perceived the general resident population as "chaotic," untrustworthy, and discussed avoiding confrontational and negative residents, many women $(n=14)$ formed one or two close friendships. Ten of these 14 women were the ones who described the general resident population in a negative way. Participants often discussed forming friendships with someone similar to them: "she is more like me." These similarities varied but often consisted of sharing common life experiences. Observations of resident interactions, and review of case files, indicated women formed friendships with those who shared similar socioeconomic backgrounds, criminal history profiles, or were of the same age. For many participants, these friendships were developed during their incarceration. New friendships were often formed when sharing common rooms or the same job:

I have two very close friends that I love. In the five years, I have three close friends. One is already home and doing great. And two, thank God, I am living with upstairs. I met them in Clinton. Formed a very close friendship. Other than that, no never. (Maureen)

One of Maureen's friends shared similar life experiences. They were both first time offenders, from middle class backgrounds, and previously worked in the financial field. Another resident, Jody, spoke about leaning on her roommates for support:

I go to my roommates. Or I go to any one of the staff, but I usually just hang out with my roommate Marta. You know, certain things we talk about we're just like-we click. Like we have the same outlook on life.

Jody and Marta were similar in age, both had an extensive history of substance abuse, and shared similar criminal backgrounds. When asking Rosa who she leans on for emotional support she described a relationship with another halfway house resident. She spoke about a friendship with a resident she knew from the same neighborhood. They have known each other from the "street" and maintain their friendship because they have been incarcerated together several times. Rosa described talking about personal problems with her friend:

I know her from the street and we are very close. She calls me mom. Right now she is my roomy again. We happen to be roomies every time we go somewhere [prison]. We talk about like if she has problems. I talk to her, she talks to me, we talk to each other. 
Another participant, Annie, spoke about developing a relationship with a resident similar to her: "I became close friends with Emme. But nobody else. Some people are just not on my level." Emme, like other residents who developed friendships, connected well with women of the same socioeconomic background and life aspirations. Several participants, including Annie, discussed maintaining the friendship once released from the halfway house. "There is a friendship there, we will always stay in touch regardless."

Even though most women in the house described the overall resident population as chaotic, including those who formed friendships, small closeknit relationships with women of similar backgrounds naturally evolved. Although the impact of these prosocial relationships on residents' program progress was not examined closely, the fact that women were able to develop and maintain supportive friendships indicates that these connections were part of their adjustment to the setting.

\section{DISCUSSION}

The purpose of this study was to understand women's experiences in a community correction facility by examining perceptions of the nonprogrammatic features related to staff characteristics and interactions, the environmental context, and resident relationships. The nuanced findings from this study suggest that relationships with staff and how residents are treated by staff play a role in how well an individual adjusts to the environment. The substance abuse and gender-responsive literature discussed in this article provides support for creating program settings that are therapeutic and consist of positive relationship dynamics. Components of the halfway house setting were consistent with the literature-particularly the supportive client-staff relationships, the feelings of psychological safety in the way staff treated residents, and the physical security of the building as a protective environment from the outside neighborhood. Although the overall social culture inside the house was not cohesive amongst residents, women built small support systems with those they trusted.

This study is not without limitations. While qualitative research may be the best method for gathering perceptions of a phenomenon, due to the small sample size and nature of data collection this method does not allow for generalizing findings to other female community correction programs. Additionally, the findings may only reflect the time period in which the study was conducted. It is possible that changes have been made at the halfway house and residents currently participating in the program may share different viewpoints. Another limitation is that this study did not ask program staff or administrators about resident relationships or their own interactions with residents. Gathering this data is something that should be collected in the future to generate a global understanding of the context of 
community correction programs. Regardless of these limitations, the study's findings support the gender-responsive and substance abuse literature on the importance of strengthening in-program relationships and other aspects of the program environment.

Understanding in-program relationships and setting features have important implications for enhancing correctional program models for women. First, the findings from this study support the empirical evidence that effective program staff matter. Research on staff-client relationships indicates that when clients have good relationships with staff they have greater changes in attitudes and behavior (Palmer, 1995). Additional research finds staff with empathetic and warmhearted characteristics motivate clients (Dowden \& Andrews, 2004; McMurran \& Ward, 2004). If staff-client relationships are essential for in-program success, as indicated in the literature and suggested from this study, program models should ensure that these relationships are nurtured. To start, program administrators should be selective when hiring staff that work directly with clients. Identifying staff with empathetic qualities, the ability to consistently and effectively use authority, and apply problem-solving techniques should be a priority. Early and on-going training on the CCP, ways to properly interact with clients, and techniques of motivation should also be implemented as part of staff development.

A second program recommendation involves attending to the relationships among clients within the setting. Halfway house residents often spend many months, sometimes over a year, within a single program setting. Their associations within this setting, although only temporary, may impact women's development during this crucial transitional phase. Program designers should pay attention to the importance of developing supportive relationships among everyone in the treatment setting. As evident from the substance abuse literature, developing and maintaining supportive staff and peer relationships influences program success (Welsh \& McGrain, 2008; Hiller et al., 2002; Simpson, 1997).

Third, this study hints at the impact neighborhood context may have on women's adjustment to programs. Participants originally from the area, especially women previously involved in the drug culture of the community, used the halfway house to get reacquainted with the community. Having staff readily available to help them cope with the "triggers" from the neighborhood was perceived as a positive factor. Women not from the area, however, were forced to deal with the additional stress of living in an unfamiliar place. From a practical viewpoint, releasing women to programs near their home communities allows them to reconnect with the people and places they are familiar with. Women not from the halfway house area had to first readjust to that community, followed by a second readjustment to their home community. Although this study did not follow-up with women once released, future research should examine whether the location in which halfway houses are situated impacts the reentry experience. 
To conclude, future evaluation research on correctional programs should pay attention to the nonprogrammatic factors discussed in this study, including how individuals adjust to the various aspects of the program setting. Whether these nonprogrammatic factors have a direct impact on outcomes, participation levels, adjustment, or client motivation should be studied further.

\section{NOTES}

1. Women referred to Edna Mahan Correctional Facility as "Clinton" because the prison was formerly called Clinton Correctional Facility.

2. This resident owned her own business prior to her incarceration. It could not be confirmed that she still operated this business while residing at the halfway house.

\section{REFERENCES}

Andrews, D. A. (2006). Enhancing adherence to risk-need-responsivity: Making quality a matter of policy. Criminology and Public Policy, 5(3), 595-602.

Andrews, D. A. (2011). The impact of nonprogrammatic factors on criminal-justice interventions. Legal and Criminological Psychology, 16, 1-23.

Andrews, D. A., \& Bonta, J. (2010). The psychology of criminal conduct (5th ed.). Newark, NJ: Lexis Nexis/Matthew Bender.

Andrews, D. A., \& Kiessling, J. J. (1980). Program structure and effective correctional practices. A summary of the CaVIC research. In R. R. Ross \& P. Gendreau (Eds.), Effective correctional treatment (pp. 439-463). Toronto, Canada: Butterworth.

Andrews, D. A., Bonta, J., \& Hoge, R. D. (1990). Classification for effective rehabilitation: Rediscovering psychology. Criminal Justice and Behavior, 17(1), 19-52.

Andrews, D. A., Zinger, I., Hoge, R. D., Bonta, J., Gendreau, P., \& Cullen, F. T. (1990). Does correctional treatment work? A clinically-relevant and psychologicallyinformed meta-analysis. Criminology, 28, 369-404.

Atlas.ti (Version 7) [Computer Software]. Berlin, Germany: Atlas.ti.

Austin, J., Bloom, B., \& Donahue, T. (1992). Female offenders in the community: An analysis of innovative strategies and programs. National Council on Crime and Delinquency. Washington, DC: U.S. Department of Justice, National Institute of Corrections.

Bloom, B., Owen, B., \& Covington, S. (2003). Gender-responsive strategies: Research, practice and guiding principles for women offenders. Washington, DC: U.S. Department of Justice, National Institute of Corrections.

Bradley, R. G., \& Davino, K. M. (2002). Women's perceptions of the prison environment: When prison is "the safest place I've ever been." Psychology of Women Quarterly, 26, 351-359.

Broome, K. M., Knight, D. K., Knight, K., Hiller, M. L., \& Simpson, D. D. (1997). Peer, family, and motivational influences on drug treatment process and recidivism for probationers. Journal of Clinical Psychology, 53(4), 387-397.

Charmaz, K. (2006). Constructing grounded theory: A practical guide through qualitative analysis. Thousand Oaks, CA: Sage. 
Covington, S. S. (2003). A women's journey home: Challenges for female offenders. In J. Travis, \& M. Waul (Eds.), Prisoners once removed (pp. 67-103). Washington DC: Urban Institute.

Covington, S. (1998). The relational theory of women's psychological development: Implications for the criminal justice system. In R. Zaplin (Ed.), Female crime E delinquency: Critical perspectives \& effective interventions (pp. 113-131). Gaithersburg, MD: Aspen.

Covington, S. S., \& Bloom, B. E. (2006). Gender-responsive treatment and services in correctional settings. Women \& Therapy, 29(3/4), 9-33.

Day, A., Casey, S., Vess, J., \& Huisy, G. (2012). Assessing the therapeutic climate of prisons. Criminal Justice and Behavior, 39(2), 156-168.

Dowden, C., \& Andrews, D. A. (1999). What works for female offenders: A metaanalytic review. Crime and Delinquency, 45(4), 438-452.

Dowden, C., \& Andrews, D. A. (2004). The importance of staff practices in delivering effective correctional treatment: A meta-analysis of core correctional practices. International Journal of Offender Therapy and Comparative Criminology, 48, 203-214.

Gehring, K. S., Van Voorhis, P., \& Bell, V. R. (2010). "What Works" for female probationers. An evaluation of the Moving On program. Women, Girls, and Criminal Justice, 11(1), 6-10.

Gendreau, P. (1996). Offender rehabilitation: What we know and what needs to be done. Criminal Justice and Behavior, 23, 144-161.

Gendreau, P., \& Goggin, C. (1996). Principles of effective correctional programming. Forum on Corrections, 8(3), 38-41.

Gilligan, C. (1982). In a different voice. Cambridge, MA: Harvard University Press.

Henriquez, Z. W., \& Jones-Brown, D. (2000). Prisons as safe havens for African American women. In M. Markowitz \& D. D. Jones-Brown (Eds.), The system in Black and White: Exploring the Connections between race, crime and justice (pp. 267-274). Westport, CT: Praeger.

Hiller, M. L., Knight, K., Leukefeld, C., \& Simpson, D. D. (2002). Motivation as a predictor of therapeutic engagement in mandated residential substance abuse treatment. Criminal Justice Behavior, 29, 56-75.

Kendall, K. (1993). Literature review of therapeutic services for women in prison. Ottawa, Canada: Correctional Service of Canada.

Koons, B. A., Burrow, J. D., Morash, M., \& Bynum, T. (1997). Expert and offender perceptions of program elements linked to successful outcomes for incarcerated women. Crime and Delinquency, 43(4), 512-532.

Kruttschnitt, C., Gartner, R., \& Miller, A. (2000). Doing her own time? Women's responses to prison in the context of the old and the new penology. Criminology, 38, 681-718.

Latessa, E. J., Cullen, F. T., \& Gendreau, P. (2002). Beyond correctional quackery. Professionalism \& the possibility of effective treatment. Federal Probation, 66(2), 43-49.

Lipsey, M. W. (1995). What do we learn from 400 research studies on the effectiveness of treatment with juvenile delinquents? In J. McGuire (Ed.), What works: Reducing reoffending: Guidelines from research and practice (pp. 63-78). Chichester, UK: Wiley. 
Lowenkamp, C. T., Latessa, E. J., \& Smith, P. (2006). Does correctional program quality really matter? The impact of adhering to the principles of effective intervention. Criminology and Public Policy, 5(3), 201-220.

Martinson, R. (1974). What works? Questions and answers about prison reform. Public Interest, 10, 22-54.

McMurran, M., \& Ward, T. (2004). Motivating offenders to change in therapy: An organizing framework. Legal and Criminological Psychology, 9, 295-311.

Messina, N., Grella, C., Cartier, J., \& Torres, S. (2010). A randomized experimental study of gender-responsive substance abuse treatment for women in prison. Journal of Substance Abuse Treatment, 38, 97-107.

Miller, J. B. (1986). Toward a new psychology of women. Boston, MA: Beacon Press. Moos, R. (1975). Evaluating correctional and community settings. New York, NY: Wiley.

Morash, M., Bynum, T. S., \& Koons, B. A. (1995). Findings from the National Study of Innovative and Promising Programs for Women Offenders. East Lansing, MI: Michigan State University, School of Criminal Justice.

Owen, B. (1998). "In the mix": Struggle and survival in a women's prison. Albany, NY: University of New York Press.

Palmer, T. (1995). Programmatic and non-programmatic aspects of successful intervention: New directions for research. Crime \& Delinquency, 41, 100-131.

Simpson, D. D. (1997). Patient engagement and duration of treatment (Unpublished paper funded by National Institute on Drug Abuse. Grant No. R01DA06162). Fort Worth, TX: Texas Christian University, Institute of Behavioral Research.

Smith, B. W., Maume, M. O., \& Reiner, S. M. (1997). Perceptions of social climate in a juvenile correctional institution. Journal of Offender Rehabilitation, 25(1/2), 143-162.

Strauss, A., \& Corbin, J. (1998). Basics of qualitative research: Techniques and procedures for developing grounded theory. Thousand Oaks, CA: Sage.

Toch, H. (1977). Living in prison: The ecology of survival. New York, NY: Macmillan.

Van Tongeren, D. R., \& Klebe, K. J. (2009). Reconceptualizing prison adjustment: A multidimensional approach exploring female offenders' adjustment to prison life. The Prison Journal, 90(48), 48-68.

Welsh, W. N., \& McGrain, P. N. (2008). Predictors of therapeutic engagement in prison-based drug treatment. Drug and Alcohol Dependence, 96, 271-280.

Wright, K. N. (1985). Developing the prison environment inventory. Journal of Research in Crime and Delinquency, 22, 257-277.

Wright, K. N. (1993). Prison environment and behavioral outcomes. Journal of Offender Rehabilitation, 20, 93-113.

Wright, E. M., Van Voorhis, P., Salisbury, E., \& Bauman, A. (2009). Gender-responsive prisons: Lessons from the NIC/UC Gender-Responsive Classification Project. Women, Girls, and Criminal Justice, 10, 85-87; 95-96. 